\title{
Assessing hydrological effects of human interventions on coastal systems: numerical applications to the Venice Lagoon
}

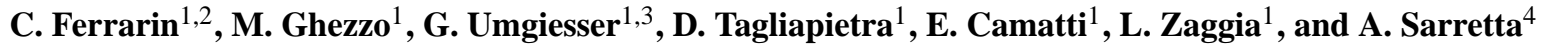 \\ ${ }^{1}$ CNR - National Research Council of Italy, ISMAR - Marine Sciences Institute in Venice, Castello 2737/f, \\ 30122 Venice, Italy \\ ${ }^{2} \mathrm{CNR}$ - National Research Council of Italy, IAMC - Institute for the Coastal Marine Environment in Oristano, \\ 090782 Torregrande, Oristano, Italy \\ ${ }^{3}$ Coastal Research and Planning Institute, CORPI, Klaipeda University, H. Manto 84, 92294 Klaipeda, Lithuania \\ ${ }^{4}$ CNR - National Research Council of Italy, ISMAR - Marine Sciences Institute in Bologna, Via Gobetti 101, \\ 40129 Bologna, Italy
}

Correspondence to: C. Ferrarin (c.ferrarin@ismar.cnr.it)

Received: 26 November 2012 - Published in Hydrol. Earth Syst. Sci. Discuss.: 18 December 2012

Revised: 11 March 2013 - Accepted: 14 April 2013 - Published: 3 May 2013

\begin{abstract}
The hydrological consequences of historical, contemporary and future human activities on a coastal system were investigated by means of numerical models. The changes in the morphology of the Lagoon of Venice during the last century result from the sedimentological response to the combined effects of human interventions on the environment and global changes. This study focuses on changes from 1927 to 2012 and includes the changes planned for the protection of the city of Venice from storm surges and exceptional tides under future sea level rise scenarios. The application of a hydrodynamic model allowed for the analysis of the morphological effects on the lagoon circulation, the interaction with the sea and the internal mixing processes. The absolute values of the exchange between the lagoon and sea increased from 1927 to 2002 (from 3900 to $4600 \mathrm{~m}^{3} \mathrm{~s}^{-1}$ ), while the daily fraction of lagoon water volume exchanged decreased. At the same time, the flattening of the lagoon and loss of morphological heterogeneity enhanced the internal mixing processes driven by the tide and wind, reducing thus the overall water renewal time from 11.9 days in 1927 to 10.8 days in 2002. Morphological changes during the last decade reduced the water exchange through the inlets and induced an increase of the basin-wide water renewal time of 0.5 day. In the future, Venice Lagoon will evolve to a more restricted environment due to sea level rise, which increases the lagoon volume, and periodical closure of the lagoon from the sea during flooding events, which reduces the communi-
\end{abstract}

cation with the open sea. Therefore, the flushing capacity of the lagoon will decrease considerably, especially in its central part. Furthermore, some considerations on the impact of the hydromorphological changes on the ecological dynamics are proposed.

\section{Introduction}

Lagoons are ephemeral environments from an geological point of view and are naturally subjected to rapid morphological changes on a very short timescale. Their evolution depends on the interaction between natural processes, human activities and hydromorphological responses to such activities (Kjerfve and Magill, 1989). Hydrodynamics determine most of the physical and biogeochemical processes affecting coastal and lagoon environments (Viaroli et al., 2007; PérezRuzafa et al., 2007, 2011; Roselli et al., 2013). Man-induced hydromorphological modifications can therefore drastically alter the hydraulic forcing and consequently also the ecological status of such a highly dynamic environment (Tagliapietra et al., 2009).

Investigating hydromorphology of a lagoon requires a large amount of information, which in most cases cannot be easily provided. Only in few cases, i.e. Aveiro Lagoon (Duck and da Silva, 2012), Venice Lagoon (Molinaroli et al., 2007; Sarretta et al., 2010) and San Pablo Bay (Jaffe et al., 
2007), the available dataset allows detailed geological and geomorphological investigations. On the other side, numerical models provide a powerful tool for investigating the response of the lagoon hydrodynamics to historical or even future engineering interventions (Gong et al., 2008; Carniello et al., 2009; Ghezzo et al., 2010; Bruneau et al., 2011).

Many morphometric and hydrological parameters have been used to characterize and classify coastal lagoons (Chubarenko et al., 2005). Among the hydrological parameters, the water transport timescale has been widely used in this context, since it is an integrative variable providing an overall estimate of the lagoon hydrodynamics. The water transport timescale has been regarded as fundamental parameter in understanding chemical and ecological dynamics in lagoon environments (Gamito et al., 2005; Gong et al., 2008). Several definitions of transport timescales exist, referring to different concepts. There are several studies describing and comparing different transport timescales (Takeoka, 1984; Monsen et al., 2002; Jouon et al., 2006; Liu et al., 2008; Cucco et al., 2009; de Brye et al., 2012). Our intent is not to debate this issue, but to provide insight on the applicability of such an indicator.

The aim of this study was to investigate the hydrological regime and renewal capacity of the heavily modified Venice Lagoon via a modelling approach following the morphological changes carried out from 1927 to 2012 and the future sea level rise (SLR) scenarios. The progressive change of the lagoon morphology was represented by adopting four numerical grids, with different coastline and bathymetry, corresponding to the situation of the lagoon in year 1927, 1970, 2002 and 2012. Furthermore, future scenarios were carried out simulating sea level rise and the closure of the mobile barriers at the inlets during flooding events.

As anthropogenic influences on aquatic environments increase, there is considerable scientific and practical interest in understanding how the ecological components will respond to multiple stressors. Therefore, in the last part of this study, some hydroecological considerations are presented to improve our understanding of ecological changes that happened in the Lagoon of Venice during last decades and to hypothesize some implications in future scenarios.

\section{Study area}

Venice Lagoon, a coastal system located in the northwest Adriatic Sea (Fig. 1), covers roughly an area of $500 \mathrm{~km}^{2}$; its major axis is oriented north-east to south-west. It is characterized by a complex network of channels, intertidal flats and shoals. Currently, a few principal deep channels (maximum depth around $15 \mathrm{~m}$ ) cross an area of very shallow water with an average depth on the order of $1 \mathrm{~m}$. The three inlets are called, from north to south, Lido, Malamocco and Chioggia and are from about 500 to about $900 \mathrm{~m}$ wide and up to $25 \mathrm{~m}$ deep.

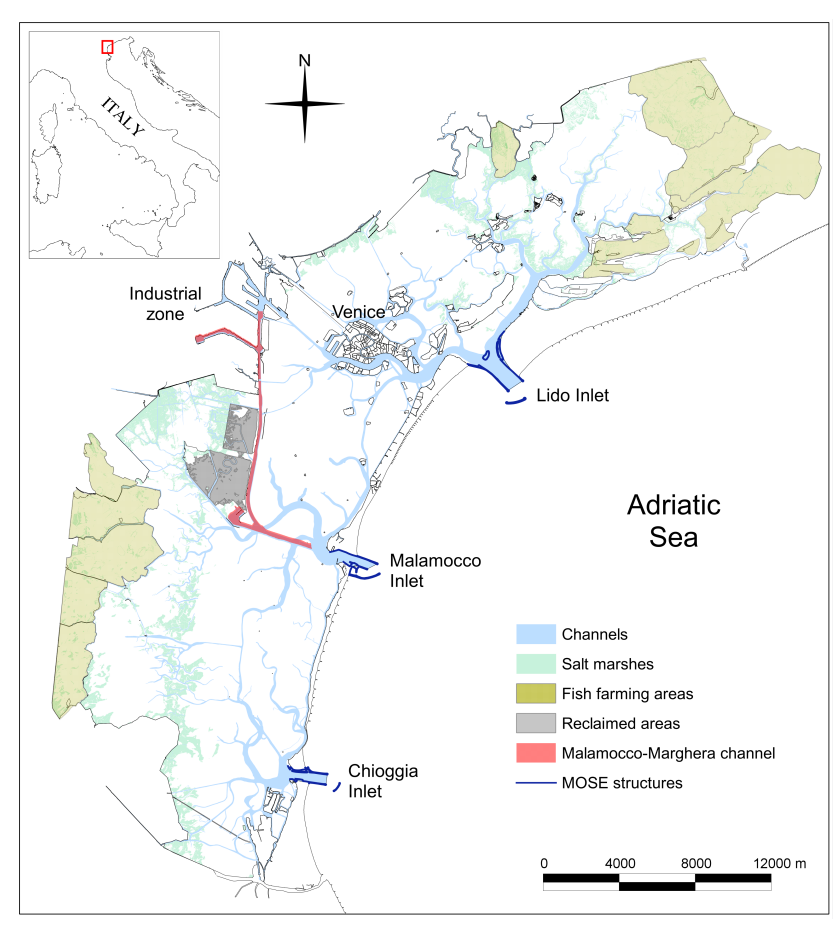

Fig. 1. The Lagoon of Venice in its present configuration (2012). Major morphological types (channels, salt marshes and fish farming areas) and modifications (reclaimed area, Malamocco-Marghera channel and MoSE structures at the inlets) are illustrated.

The morphological evolution of the Lagoon of Venice has been strongly influenced by the human presence since remote times. From a few centuries after its colonisation, the Venetians tried to modify the environment in the attempt to preserve economic interests and for defense purposes (Guerzoni and Tagliapietra, 2006; Solidoro et al., 2010). Priority was given to the management of freshwater and sediment yield of the drainage-basin tributaries to prevent sedimentation in marginal areas, which exposed the city to the threat of invasions from the mainland. The main intervention realized from the second half of the 16th century was the diversion of main rivers (Piave and Brenta) that determined a strong imbalance in the sediment budget of the lagoon. Other important issues were the protection of the barrier islands from storm waves and the accessibility to the port channel. The navigation channel at the northern end was endangered by the long-shore transport of sand that caused the formation and the SW migration of a large sand bar immediately outside of the lagoon. Several measures were taken throughout the centuries but a definitive solution was found only at the end of the 19th century with the construction of long jetties that joined the flow of three previous inlets in a single self dredging channel which is presently known as Lido Inlet (D'Alpaos, 2010).

In this study we focus on changes that occurred from 1927, after the protection of the inlets with jetties, to the 
Table 1. Morphometric characteristics of the Venice Lagoon in the 1927, 1970, 2002 and 2012 scenarios in terms of lagoon surface, mean water depth, water volume, extension of salt marshes, total cross-sectional area of inlets $\left(S_{\text {inlet }}\right)$ and openness parameter $\left(P_{\text {open }}\right)$, defined as the ratio between $S_{\text {inlet }}$ and the lagoon surface area.

\begin{tabular}{lcccccc}
\hline Scenario & $\begin{array}{c}\text { Surface } \\
\left(10^{8} \mathrm{~m}^{2}\right)\end{array}$ & $\begin{array}{c}\text { Mean depth } \\
(\mathrm{m})\end{array}$ & $\begin{array}{c}\text { Volume } \\
\left(10^{8} \mathrm{~m}^{3}\right)\end{array}$ & $\begin{array}{c}\text { Salt marshes } \\
\left(10^{8} \mathrm{~m}^{2}\right)\end{array}$ & $\begin{array}{c}S_{\text {inlet }} \\
\left(\mathrm{m}^{2}\right)\end{array}$ & $\begin{array}{c}P_{\text {open }} \\
\left(10^{-5}\right)\end{array}$ \\
\hline 1927 & 4.260 & 1.39 & 5.055 & 0.68 & 21001 & 4.93 \\
1970 & 4.150 & 1.61 & 6.372 & 0.35 & 23341 & 5.62 \\
2002 & 4.150 & 1.85 & 6.596 & 0.32 & 23758 & 5.72 \\
2012 & 4.146 & 1.85 & 6.577 & 0.32 & 23468 & 5.66 \\
\hline
\end{tabular}

present-day (2012). For this period detailed bathymetric and morphological data are available (Sarretta et al., 2010). The main morphological changes are:

- salt marshes' destruction from 1927 to 1960 to reclaim land for the construction of the industrial zone (a total of $22 \mathrm{~km}^{2}$ ), together with Venice airport and urban development on the lagoon-side of the city of Mestre (S. Giuliano), the latter two occupying a further $5 \mathrm{~km}^{2}$;

- dredging of the Malamocco-Marghera ship channel in the central part of the lagoon from 1960 to 1970;

- restoration activities, which included salt marsh stabilization up to the construction of artificial salt marshes, since the early 1990s;

- inlet reconfiguration from 2002 to 2012 to construct the mobile barrier system (MoSE, from the Italian acronym for Experimental Electromechanic Module) for defending the city of Venice from floods caused by exceptional tides and storm surges. The main changes are the construction of an artificial island in the middle of the Lido inlet, and the creation of breakwaters and refuge harbours in each inlet. The MoSE project entails building mobile barriers at the bottom of each inlet that, when flood events threaten to become critical, will rise and shut off the lagoon from the sea. The level of $110 \mathrm{~cm}$ (above sea level reference datum), which conventionally defines the exceptional flooding event (locally called acqua alta, high water), is the value above which the gates would close to separate the lagoon from the sea (Carbognin et al., 2010). MoSE should be fully operative in 2016. Some hydrodynamic consequences of inlet modification and closure have been previously investigated through numerical models by Melaku Canu et al. (2001), Umgiesser and Matticchio (2006) and Ghezzo et al. (2010).

A set of quantitative geo-morphometric parameters of the Venice Lagoon in the 1927, 1970, 2002 and 2012 scenarios is reported in Table 1. The main morphological alterations in the period 1970-2002 were an extensive deepening of the lagoon (as a result of subsidence and loss of sediment), and the areal diminution of the salt marshes (Carniello et al., 2009; Sarretta et al., 2010). Salt marshes decreased by more than $50 \%$ from $68 \mathrm{~km}^{2}$ in 1927 to $32 \mathrm{~km}^{2}$ in 2002 , while the mean depth of the whole lagoon varied from a value of $1.39 \mathrm{~m}$ in 1927 to $1.85 \mathrm{~m}$ in 2002 . The severe erosion of tidal flats (average deepening of $40 \mathrm{~cm}$ ) in the central lagoon from 1970 and 2000 is probably the morphological response of the lagoon to the excavation of Malamocco-Marghera navigation channel in 1966-1969 $\left(30-5010^{6} \mathrm{~m}^{3}\right.$ of sediments disposed in landfill areas outside the lagoon) (Sarretta et al., 2010). The total cross-sectional area of the inlets $\left(S_{\text {inlet }}\right)$ increased from 1927 to 2002, as well as the openness parameter $P_{\text {open }}$, defined as the ratio between $S_{\text {inlet }}$ and the lagoon surface area (from $4.93 \times 10^{-5}$ to $5.72 \times 10^{-5}$ ). Both $S_{\text {inlet }}$ and $P_{\text {open }}$ reduced slightly after the construction of the MoSE infrastructures.

The sea level reference datum is about $27-28 \mathrm{~cm}$ higher than the IGM42 datum used for the bathymetries (Sarretta et al., 2010) due to subsidence and sea level rise in the last century. The vertical datum difference was accounted in the simulations.

\section{Materials and methods}

A framework of numerical models (SHYFEM, freely available online at www.ismar.cnr.it/shyfem; Umgiesser et al., 2004) was applied to the surface domain of Venice Lagoon and its adjacent shore. Water renewal times are estimated by computing the dispersal and fate of the conservative tracer. The model is especially well suited to very shallow areas and has been successfully applied to several shallow water coastal systems (Umgiesser et al., 2004; Ferrarin and Umgiesser, 2005; Ferrarin et al., 2008, 2010b; De Pascalis et al., 2011).

\subsection{Hydrodynamic model description}

The 3-D hydrodynamic model SHYFEM applied here uses finite elements for horizontal spatial integration and a semiimplicit algorithm for integration in time (Umgiesser and Bergamasco, 1995; Umgiesser et al., 2004). 
The primitive equations, vertically integrated over each layer, are

$$
\begin{aligned}
& \frac{\partial U_{1}}{\partial t}+u_{1} \frac{\partial U_{1}}{\partial x}+v_{1} \frac{\partial U_{1}}{\partial y}-f V_{1}=-g h_{1} \frac{\partial \zeta}{\partial x}-\frac{h_{1}}{\rho_{0}} \frac{\partial p_{\mathrm{a}}}{\partial x} \\
&+\frac{1}{\rho_{0}}\left(\tau_{x}^{\mathrm{top}(l)}-\tau_{x}^{\mathrm{bottom}(l)}\right)+\frac{\partial}{\partial x}\left(A_{\mathrm{h}} \frac{\partial U_{1}}{\partial x}\right)+\frac{\partial}{\partial y}\left(A_{\mathrm{h}} \frac{\partial U_{1}}{\partial y}\right) \\
& \frac{\partial V_{1}}{\partial t}+u_{1} \frac{\partial V_{1}}{\partial x}+v_{1} \frac{\partial V_{1}}{\partial y}+f U_{1}=-g h_{1} \frac{\partial \zeta}{\partial y}-\frac{h_{1}}{\rho_{0}} \frac{\partial p_{\mathrm{a}}}{\partial y} \\
&+\frac{1}{\rho_{0}}\left(\tau_{y}^{\mathrm{top}(l)}-\tau_{y}^{\mathrm{bottom}(l)}\right)+\frac{\partial}{\partial x}\left(A_{\mathrm{h}} \frac{\partial V_{1}}{\partial x}\right)+\frac{\partial}{\partial y}\left(A_{\mathrm{h}} \frac{\partial V_{1}}{\partial y}\right) \\
& \frac{\partial \zeta}{\partial t}+\sum_{l=1}^{\mathrm{L}} \frac{\partial U_{1}}{\partial x}+\sum_{l=1}^{\mathrm{L}} \frac{\partial V_{1}}{\partial y}=0
\end{aligned}
$$

with $l$ indicating the vertical layer, $\left(U_{1}, V_{1}\right)$ the horizontal transport at each layer (integrated velocities), $f$ the Coriolis parameter, $p_{\mathrm{a}}$ the atmospheric pressure, $g$ the gravitational acceleration, $\zeta$ the sea level, $\rho_{0}$ the average density of sea water, $\tau$ the internal stress term at the top and bottom of each layer, $h_{1}$ the layer thickness.

The boundary conditions for stress terms are

$$
\begin{aligned}
& \tau_{x}^{\text {surface }}=c_{\mathrm{D}} \rho_{\mathrm{a}} w_{x} \sqrt{w_{x}^{2}+w_{y}^{2}} \\
& \tau_{y}^{\text {surface }}=c_{\mathrm{D}} \rho_{\mathrm{a}} w_{y} \sqrt{w_{x}^{2}+w_{y}^{2}} \\
& \tau_{x}^{\text {bottom }}=c_{\mathrm{B}} \rho_{0} u_{\mathrm{L}} \sqrt{u_{\mathrm{L}}^{2}+v_{\mathrm{L}}^{2}} \\
& \tau_{y}^{\text {bottom }}=c_{\mathrm{B}} \rho_{0} v_{\mathrm{L}} \sqrt{u_{\mathrm{L}}^{2}+v_{\mathrm{L}}^{2}}
\end{aligned}
$$

where $c_{\mathrm{D}}$ is the wind drag coefficient, $c_{\mathrm{B}}$ is the bottom friction coefficient, $\rho_{\mathrm{a}}$ is the air density, $\left(w_{x}, w_{y}\right)$ are the zonal and meridional components of the wind velocity, respectively, and $\left(u_{\mathrm{L}}, v_{\mathrm{L}}\right)$ is the water velocity in the lowest layer.

Smagorinsky's formulation (Smagorinsky, 1963; Blumberg and Mellor, 1987) is used to parameterize the horizontal eddy viscosity $\left(A_{\mathrm{h}}\right)$. For the computation of the vertical viscosities, a turbulence closure scheme was used. This scheme is an adaptation of the $k-\epsilon$ module of GOTM (General Ocean Turbulence Model) described in Burchard and Petersen (1999).

The model uses a semi-implicit algorithm for integration over time, which has the advantage of being unconditionally stable with respect to gravity waves, bottom friction and Coriolis terms, and allows transport variables to be solved explicitly without solving a linear system (Umgiesser et al., 2004). The Coriolis term and pressure gradient in the momentum equation, and the divergence terms in the continuity equation are treated semi-implicitly. Bottom friction and vertical viscosity are treated fully implicitly for stability reasons due to the shallow nature of the lagoon, while the remaining terms (advective and horizontal diffusion terms in the momentum equation) are treated explicitly (Umgiesser et al., 2004; Umgiesser and Bergamasco, 1995). The maximum allowable time step in the simulation was set to $100 \mathrm{~s}$, and the model adopts automatic sub-stepping over time to enforce numerical stability with respect to advection and diffusion terms.

\subsection{Water renewal time, return flow factor and openness with the sea}

In this section we describe the three hydrological parameters, based on numerical model results, which were used in this study to characterize the hydromorphological evolution of the lagoon.

Assuming that advection and diffusion are the main physical processes that influence the cleaning capacity of the lagoon's ecosystem (Rodhe, 1992), the water renewal time was used to compute the transport time of lagoon's waters. The water renewal time (WRT) was considered as the time required for each element of the domain to replace the mass of a conservative tracer with new water (Cucco and Umgiesser, 2006; Cucco et al., 2009; Ferrarin et al., 2008). Such a transport timescale can be associated with the renewal time concept and is an adequate indicator related to the environmental health of the aquatic system (Abdelrhman, 2005; Plus et al., 2009; Ouillon et al., 2010; Hartnett et al., 2012). The model solves the 3-D advection and diffusion equation to compute the dispersal and fate of the conservative tracer, which is given by

$$
\begin{aligned}
\frac{\partial C_{1}}{\partial t} & +u \frac{\partial C_{1}}{\partial x}+v \frac{\partial C_{1}}{\partial y}+w \frac{\partial C_{1}}{\partial z}=\frac{\partial}{\partial x}\left(K_{\mathrm{H}} \frac{\partial C_{1}}{\partial x}\right) \\
& +\frac{\partial}{\partial y}\left(K_{\mathrm{H}} \frac{\partial C_{1}}{\partial y}\right)+\frac{\partial}{\partial z}\left(K_{\mathrm{V}} \frac{\partial C_{1}}{\partial z}\right)
\end{aligned}
$$

where $C_{1}$ is the concentration of the conservative tracer at layer $l, u, v$ and $w$ are the velocities, $K_{\mathrm{H}}$ and $K_{\mathrm{V}}$ are respectively the horizontal and vertical turbulent diffusion coefficients. The transport and diffusion equation is solved with a first-order explicit scheme based on the total variational diminishing (TVD) method.

To compute the WRT we refer to the mathematical expression given by Takeoka (1984), known as the remnant function. The water renewal time can then be computed for each point of the domain as (Cucco and Umgiesser, 2006)

$\tilde{\operatorname{WRT}}(x, y, z)=\int_{t=0}^{\infty} r(t, x, y, z) \mathrm{d} t$

where $r(t, x, y, z)=C(t, x, y, z) / C(0, x, y, z)$ is the local remnant function, with $C(t, x, y, z)$ the local concentration of a conservative tracer at time $t$ (s) and $C(0, x, y, z)$ its initial value. The integral in the above equation is numerically approximated in accordance with the simulation time step. To account for the residual tracer mass at the end of the simulation, local water renewal time values are subsequently corrected, assuming exponential decay of the tracer, as:

$\operatorname{WRT}(x, y, z)=\frac{\tilde{\operatorname{WRT}}(x, y, z)}{1-r(T, x, y, z)}$

where $r(T, x, y, z)$ is the local remnant function at the end of the simulation $(t=T)$. 
The volume-weighted average of local renewal times $(\overline{\mathrm{WRT}})$ equals the overall water renewal time of the basin computed as the time integral of the total concentration over the model domain, divided by the initial amount of material in the water body.

The water renewal time of a semi-closed basin can be strongly influenced by the properties of the outgoing flow and by the interaction with the coastal currents. In tidally dominated basins, for each tidal cycle, a fraction of the tracer flows out to sea during the ebb tide, but a part of it can flow back into the lagoon again during the next flood tide. Sanford et al. (1992) proposed the definition of return flow factor (RFF) as an estimate of the proportion of lagoon water flowing out to sea that returns to the basin. It can be calculated for the whole lagoon domain as

$\mathrm{RFF}=\frac{\overline{\mathrm{WRT}}-\overline{\mathrm{WRT}_{0}}}{\overline{\mathrm{WRT}}}$

where $\overline{\mathrm{WRT}}$ is the basin-wide average water renewal time and $\overline{\mathrm{WRT}_{0}}$ is the basin-wide average water renewal time calculated for the situation in which all the tracer that exits the basin vanishes. RFF ranges between 0 (no tracer return) and 1 (the whole tracer mass re-enters) (Cucco and Umgiesser, 2006).

The degree of communication with the open sea is usually measured by the openness parameter $P_{\text {open }}$, deduced by geomorphologic characteristics (Chubarenko et al., 2005). However, this parameter does not take into account the water volume of the lagoon and the real water exchange through the inlets. Therefore, in this study, the influence of the sea on general lagoon hydrology was estimated by the daily fraction of lagoon water volume exchanged with the open sea (FVE), computed as ratio between the daily flux of water from the sea to the lagoon and the basin volume.

\subsection{Simulations set-up}

The hydrodynamic numerical computation is performed on a spatial domain that represents the Venice Lagoon and its adjacent shore. The use of elements of variable sizes, typical of finite element methods, is fully exploited in order to suit the complicated geometry of the basin, the rapidly varying topographic features, and the complex bathymetry. Four numerical grids were constructed representing the morphology of the Venice Lagoon in 1927, 1970, 2002 and 2012. The numerical grid of the 2012 configuration is represented in Fig. 2. The water column is discretized into 17 vertical levels with progressively increasing thickness, varying from $1 \mathrm{~m}$ for the topmost 10 to $7 \mathrm{~m}$ for the deepest layer of the outer shelf.

The factors affecting the transport process have a high influence on the calculation of the WRT. In the Venice Lagoon, tide (about $1 \mathrm{~m}$ tidal range during spring tides) and wind are the most important forcing factors and, in particular, the direction of the wind (Bora from NE and Scirocco from SE),

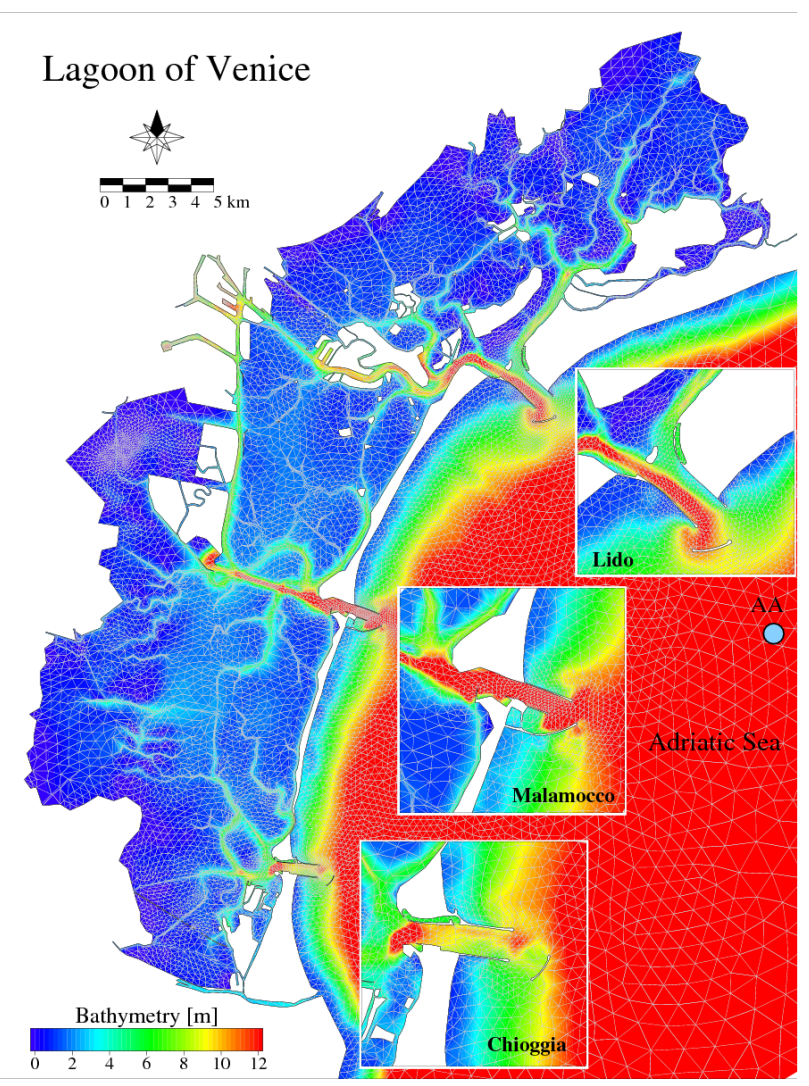

Fig. 2. Bathymetry (referred to IGM42 datum) of Venice Lagoon in the present situation (2012) and adjacent shore obtained by using finite element model grid (superimposed). The circle indicates the location of oceanographic tower Acqua Alta (AA).

the frequency, duration and intensity of wind events affects strongly the circulation regime of the lagoon and, as a consequence, the WRT. In this paper the baroclinic contribution is not considered, therefore the model results take into account only the water exchanges between the lagoon and the sea induced by the tide and wind action.

Four yearly simulations, representing the Venice Lagoon configuration in 1927, 1970, 2002 and 2012, were carried out (named Y_1927, Y_1970, Y_2002 and Y_2012). Considering that we simulate the circulation of the lagoon under realistic tide and wind forcing conditions (the selected year of reference is 2002) and that the results may depend on the initial time of the simulation, we calculated WRT every three months along one year and considered an average values of four repetitions as mean WRT for the year.

In order to investigate the effects of morphological modifications during high water condition, a set of monthly simulations was carried out (simulations named M_1927, M_1970, M_2002 and M_2012). The period of reference of these simulations is November 2002, during which seven high water events occurred. Furthermore, four additional simulations were performed for the 2012 configuration considering the 
Table 2. Simulations description and set-up.

\begin{tabular}{lcllc}
\hline Sim.name & Layout & Duration & $\begin{array}{l}\text { MoSE } \\
\text { closure }\end{array}$ & $\begin{array}{c}\text { SLR } \\
(\mathrm{cm})\end{array}$ \\
\hline Y_1927/M_1927 & 1927 & yearly/monthly & no & 0 \\
Y_1970/M_1970 & 1970 & yearly/monthly & no & 0 \\
Y_2002/M_2002 & 2002 & yearly/monthly & no & 0 \\
Y_2012/M_2012 & 2012 & yearly/monthly & no & 0 \\
\hline SLR_00 & 2012 & monthly & yes & 0 \\
SLR_10/SLR_10_NoM & 2012 & monthly & yes/no & 10 \\
SLR_30/SLR_30_NoM & 2012 & monthly & yes/no & 30 \\
SLR_50/SLR_50_NoM & 2012 & monthly & yes/no & 50 \\
\hline
\end{tabular}

closure of barriers at water level higher than $110 \mathrm{~cm}$, and increasing the boundary water level by $0,10,30$ and $50 \mathrm{~cm}$, to reproduce future sea level rise scenarios (simulations named SLR_00, SLR_10, SLR_30, SLR_50). The absence of water flux through the inlets during the rise of the barriers was simulated by increasing bottom shear stress and viscosity in the inlets area. In order to investigate the degree of choking the MoSE barriers are causing to the lagoon, we carried out three additional simulations which considers SLR without any closure of the inlets during high tide events (simulations named SLR_10_NoM, SLR_30_NoM, SLR_50_NoM).

The expected times for SLR of 10,30 and $50 \mathrm{~cm}$ can be estimated to be 2030, 2060 and 2090 by considering that recent observations find sea level tracking at the upper range of IPCC projections (Allison et al., 2009; Umgiesser et al., 2012). It is reasonable to assume that SLR will change the mean depth and volume, but it will not modify the lagoon surface since its perimeter is heavily anthropized. The aptitude of salt marshes to keep pace with SLR is a debated topic, but it has been generally found that wetlands can counteract accelerated sea level rise only in areas with high sediment input (Day et al. , 2011). Therefore, since river sediment input in the Venice Lagoon is almost absent (Day et al. , 1998), we assumed no accretion and vertical elevation gain of salt marshes with future SLR.

All simulations were forced by hourly observations of wind and water level recorded in the open sea in front of the lagoon at the oceanographic tower Acqua Alta (up to $15 \mathrm{~km}$ offshore). The characteristics of the performed simulations are summarized in Table 2.

The conservative tracer was initially released uniformly throughout the entire lagoon with a concentration corresponding to 1 , while a concentration of zero was imposed on the seaward boundary. The horizontal turbulent diffusivity was calculated using the model proposed by Smagorinsky (1963), with a Smagorinsky parameter of 0.3. Vertical diffusivities are calculated by the $k-\epsilon$ turbulence closure model.

The model application to the Venice Lagoon has been validated in previous works correctly reproducing the tidal propagation and the flows in the three inlets for the scenarios 1970, 2002 and 2012 (Umgiesser, 2000; Umgiesser

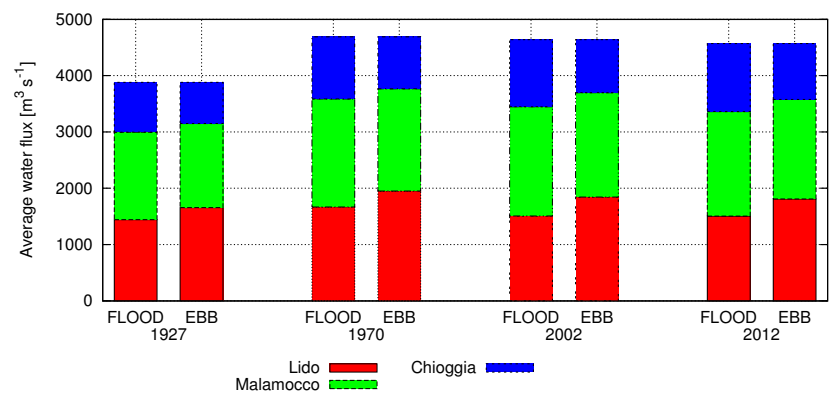

Fig. 3. Average water fluxes between the lagoon and the sea during ebb and flood tide for the four past and present situations (1927, 1970, 2002, 2012).

et al., 2004; Cucco and Umgiesser, 2006; Ferrarin et al., 2010a; Ghezzo et al., 2010). The model application for the 1927 scenario could not be validated due to lack of measurements. The numerical procedure for simulating the closure of the barrier has been successfully tested in Umgiesser and Matticchio (2006).

\section{Results}

Modelling results are divided into two sections: the first describes the yearly simulations output of the historical and contemporary layouts (1927-2012), while the second presents the fall-winter simulations results and the future sea level rise scenarios considering the shut off of the lagoon due to the MoSE barriers.

\subsection{7-2012 evolution}

The evolution of the WRTs is linked to the different situation of the bathymetry, of the lagoon perimeter and of the inlets structure, represented by the different grids. The method permits the examination of both the WRT value for the whole basin and the local WRT, with a spatial differentiation depending on the local circulation.

Model results for these simulations, as average values for the whole basin, are summarized in Table 3. Figure 3 shows that the total water exchange with the sea increases from the year 1927 to the year 1970 because of the opening of the Malamocco-Marghera channel and the deepening of the shallow areas, as indicated by the increase of volume and by land reclamation. From 2002 to 2012 the total water flow tends to reduce after the construction of the MoSE infrastructures that slightly decrease the fluxes (Ghezzo et al., 2010). From Fig. 3 it is evident that the flux through some inlets, during ebb and flood phase, does not have a symmetrical behaviour in all the considered situations. For the period 1930-2000, passing from flood to ebb phase, the flow through the Lido inlet increases, and it reduces through the Chioggia inlet, whereas Malamocco inlet maintains a balanced behaviour. With the MoSE structures almost completely in place, as for 
Table 3. Simulation results for the 1927-2012 scenarios. Results are given in terms of average sea-lagoon water fluxes, basin-wide average water renewal time and return flow factor. The last two parameters were calculated as average of four replicas.

\begin{tabular}{lccc}
\hline Sim. name & $\begin{array}{c}\text { Sea-lagoon fluxes } \\
\left(\mathrm{m}^{3} \mathrm{~s}^{-1}\right)\end{array}$ & $\begin{array}{c}\overline{\text { WRT }} \\
(\text { days })\end{array}$ & $\begin{array}{c}\text { RFF } \\
\text { (adim) }\end{array}$ \\
\hline Y_1927 & 3881 & 11.9 & 0.082 \\
Y_1970 & 4688 & 11.0 & 0.086 \\
Y_2002 & 4641 & 10.8 & 0.086 \\
Y_2012 & 4570 & 11.3 & 0.112 \\
\hline
\end{tabular}

the present situation (year 2012), even the Malamocco inlet shows a slightly unbalanced behaviour with incoming fluxes greater than the outgoing fluxes.

The basin-wide average water renewal times of the Venice Lagoon are reported in Table 3. The WRT tends to decrease from 1927 (11.9 days), to 1970 (11.0 days), until to 2002 (10.8 days). Only with the last change of the inlet morphology in 2012 (MoSE) does it tend to slightly increase (11.3 days).

Qualitatively, the spatial distribution of WRT is heterogeneous, mainly dependent on the relative distance from the inlets and on the presence of channels. The areas connected to these channels are directly influenced by the sea and consequently their water renewal times are lower (Fig. 4a). The main characteristics of WRT spatial distribution remain similar in the considered scenarios, with a gradient going from the inlets towards the inner margins of the lagoon.

The spatial distribution of the WRT difference between the different scenarios (Fig. 4b-d) and the comparison between the frequency distribution of the water renewal times, by $\%$ of volume (Fig. 5a), and the variations of the elevation, by \% of area (Fig. 5b), of the lagoon indicate that:

- From the year 1927 (red continuous line) to 1970 (green dashed line), the frequency of the highest WRT values decreases, whereas the frequency of very low WRT (around 2 days overall) increases significantly. At the same time the bathymetry of the lagoon becomes generally deeper with an overall variation of $0.5 \mathrm{~m}$. As shown in Fig. 4b, there is a general decrease of WRT over the whole lagoon.

- From the year 1970 (green dashed line) to 2002 (blue dotted line) there is an increase of the frequency of WRTs in the range of 5-8 days. This corresponds to the decrease of WRT in the central part of the lagoon (Fig. 4c), where the deepening was more intense (Sarretta et al., 2010). As shown in Fig. 5b, the areas between 0 and $-1 \mathrm{~m}$ decrease significantly, while deeper areas increase. The increase of WRT in the northern part of the lagoon and the associated increase of areas in the range $0: 1 \mathrm{~m}$ are probably due to recent construction of artificial salt marshes.
- From the year 2002 (blue dotted line) to 2012 (gray dot-dashed line) there is a general shift of water renewal time toward higher values. In particular the frequency of WRTs below 6 days decreases, whereas the number of WRTs between 6 to 10 days increases. This variation is related to the recent changes in the circulation in the three inlets, induced by the realisation of the MoSE structures at the inlets, which affect mostly the central part of the lagoon (Fig. 4d). In this period, a single dataset of bathymetry is available and elevation differences cannot be estimated.

The average value of the return flow factor for the basin slightly increases (from 0.082 to 0.086 ) from 1927 to the year 1970. This indicates that the opening of MalamoccoMarghera channel intensifies the current velocities, but retains the symmetry of the flow and therefore the amount of tracer that may come back increases. From 1970 to 2002 it maintains the same value, and finally in the year 2012 reaches the maximum value of 0.112 .

\subsection{Fall-winter simulations and future scenarios of sea level rise}

From the statistics of the local climatology, winter months, particularly November, are more frequently characterised by meteo-marine conditions favourable to the onset of storm surges (high water). Typically, southeasterly winds (Scirocco), associated to storm surges in the northern Adriatic Sea, induce an energetic circulation in the Lagoon of Venice (Umgiesser, 2000) and consequently lower water renewal times of the lagoon with respect to calm conditions (Cucco and Umgiesser, 2006).

Modelled water renewal time and the daily fraction of lagoon water volume exchanged with the open sea (FVE), the number of over threshold events and the overall time of closure of the mobile barriers at the inlets for the considered scenarios are reported in Table 4.

Numerical results of the monthly simulations for the 1927 , 1970, 2002 and 2012 scenarios show a similar trend of the yearly simulations: from 1927 to 2002 the morphological evolution implies a slow decrease in the $\overline{\mathrm{WRT}}$, while the fixed MoSE structures bring back the WRT to the values obtained in the 1927 simulation. In 1927 more than half (54\%) of the lagoon water volume was exchanged daily with the sea during strong Scirocco events. Morphological modifications so far introduced changed both the lagoon water volume and the flux through the inlets, reducing the daily fraction of water volume exchanged with the open sea ( $\mathrm{FVE}=0.49$ in 2012).

Closing the gates during high water events (for a total of $39 \mathrm{~h}$ of closure) increases the water renewal time from 8.3 to 9.4 days. The operating time of the MoSE barriers under the different sea level rise scenarios extends the modelled WRTs. The computed average water renewal time is 10.6, 12.2 and 15.2 days for an SLR of 10,30 and $50 \mathrm{~cm}$, respectively. During autumn, an SLR of $50 \mathrm{~cm}$, and the associated closure of 

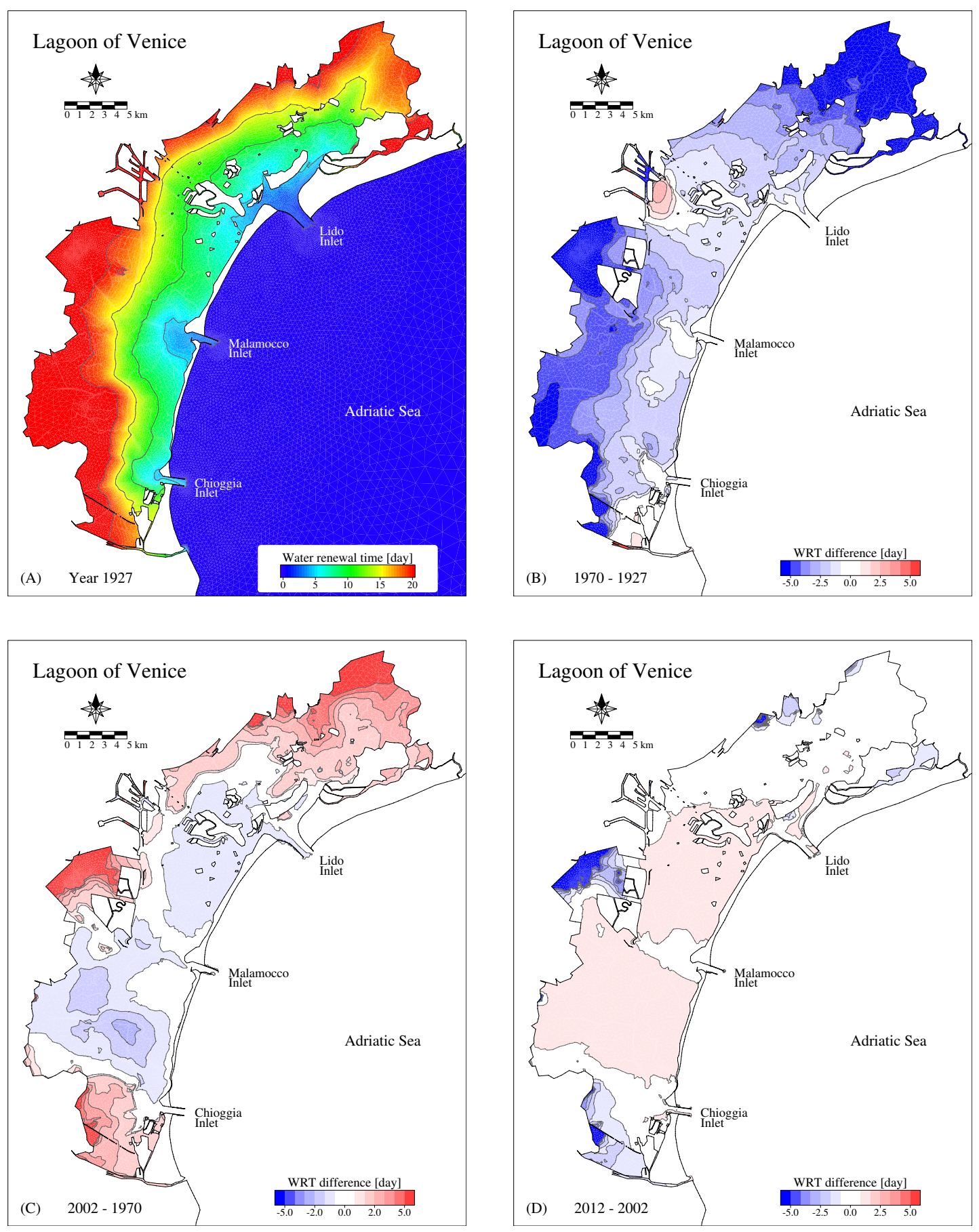

Fig. 4. Map of water renewal time computed by the model for the 1927 (A) and maps of the WRT difference (in days) between 1970 and 1927 (B), between 2002 and 1970 (C) and between 2012 and 2002 (D). WRT values were computed as average of four replicas obtained by forcing the model with water level and wind observations of year 2002.

the MoSE barriers, limit the daily water exchange with the sea to about one-sixth of the overall lagoon water volume.

The distribution of the WRTs in the lagoon for the SLR-00 scenario considering the closure of the inlets during high water events and the maps of WRT difference (in days) between the scenarios with SLR of 10,30 and $50 \mathrm{~cm}$ and the reference scenario SLR-00 are presented in Fig. 6. The effects of Scirocco winds on the water renewal capacity of the lagoon are spatially diversified with more efficiency in the southern areas than in the northern ones, where the highest WRT 

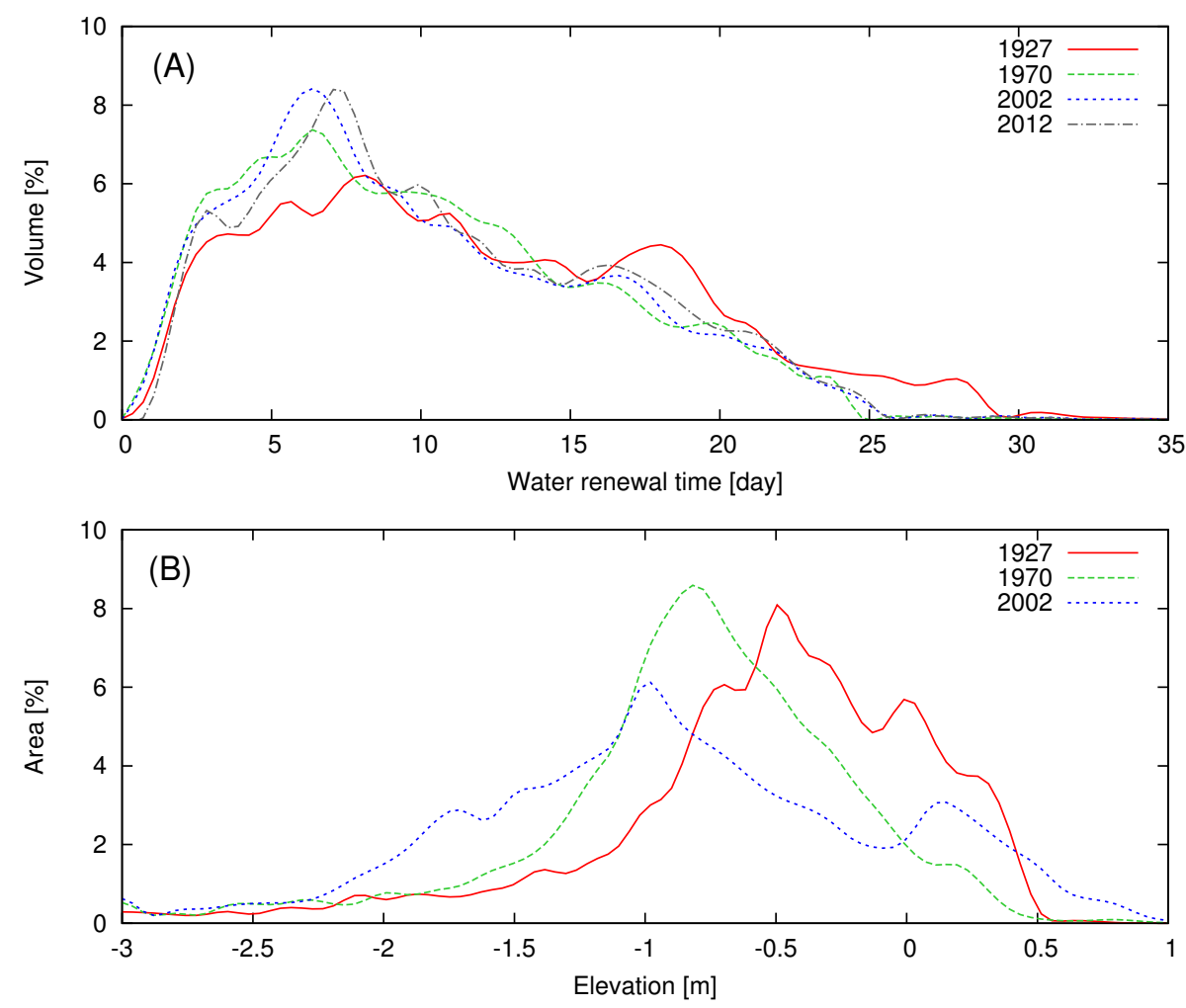

Fig. 5. Frequency distribution of water renewal time, by \% of volume (A), and elevation (referred to IGM 42 datum), by \% of area (B), for the 1927 (red continuous line), 1970 (green dashed line), 2002 (blue dotted line) and 2012 (gray dot-dashed line) scenarios. There is no available elevation dataset for the 2012 scenario and therefore the elevation over the lagoon was assumed to be unchanged from year 2002 .

Table 4. Model results of monthly simulations in terms of basinwide average water renewal time ( $\overline{\mathrm{WRT}})$ and daily fraction of water lagoon volume exchanged with the open sea (FVE). Table reports also the number of high water events and the overall closure time of barriers.

\begin{tabular}{lcccc}
\hline Sim. name & $\begin{array}{c}\text { Number of } \\
\text { high water } \\
\text { events }\end{array}$ & $\begin{array}{c}\text { Closure } \\
\text { period } \\
\text { (hours) }\end{array}$ & $\begin{array}{c}\overline{\text { WRT }} \\
\text { (days) }\end{array}$ & $\begin{array}{c}\text { FVE } \\
\text { (adim) }\end{array}$ \\
\hline M_1927 & 7 & 0 & 8.3 & 0.54 \\
M_1970 & 7 & 0 & 8.2 & 0.52 \\
M_2002 & 7 & 0 & 8.1 & 0.50 \\
M_2012 & 7 & 0 & 8.3 & 0.49 \\
\hline SLR_00 & 7 & 39 & 9.4 & 0.43 \\
SLR_10 & 10 & 60 & 10.6 & 0.41 \\
SLR_30 & 25 & 183 & 12.2 & 0.28 \\
SLR_50 & 42 & 372 & 15.2 & 0.17 \\
\hline
\end{tabular}

values are found (Fig. 6a). With increasing SLR, the WRT in the northern part of the lagoon decreases, whereas it increases in the central and in the southern sub-basins (Fig. 6bd). In these future scenarios, the spatial distribution of water renewal time seems less related to the distance from the inlets, but rather resembles a radial gradient with higher values in the central part of the lagoon (close to the city of Venice) and lower values in its southern and northern areas. The decrease of the WRT with increasing SLR in the northern parts of the lagoon is due to the inflow from the Porto di Piave Vecchia channel which is not planned to be closed during high water events. The inflow of water through the Porto di Piave Vecchia channel has a negligible effect on the mean water level in the lagoon. With an SLR of $50 \mathrm{~cm}$, the central sub-basin is expected to have under fall-winter conditions WRT values higher than 15 days. These high WRT values are found in the present situation only in the more confined inner-lagoon areas (Fig. 4d).

\section{Discussion}

\subsection{Hydromorphological evolution}

The evolution of the Venice Lagoon from the recent historical period to the future is summarized in Fig. 7 in terms of basinwide average water renewal time computed for the monthly simulation. 

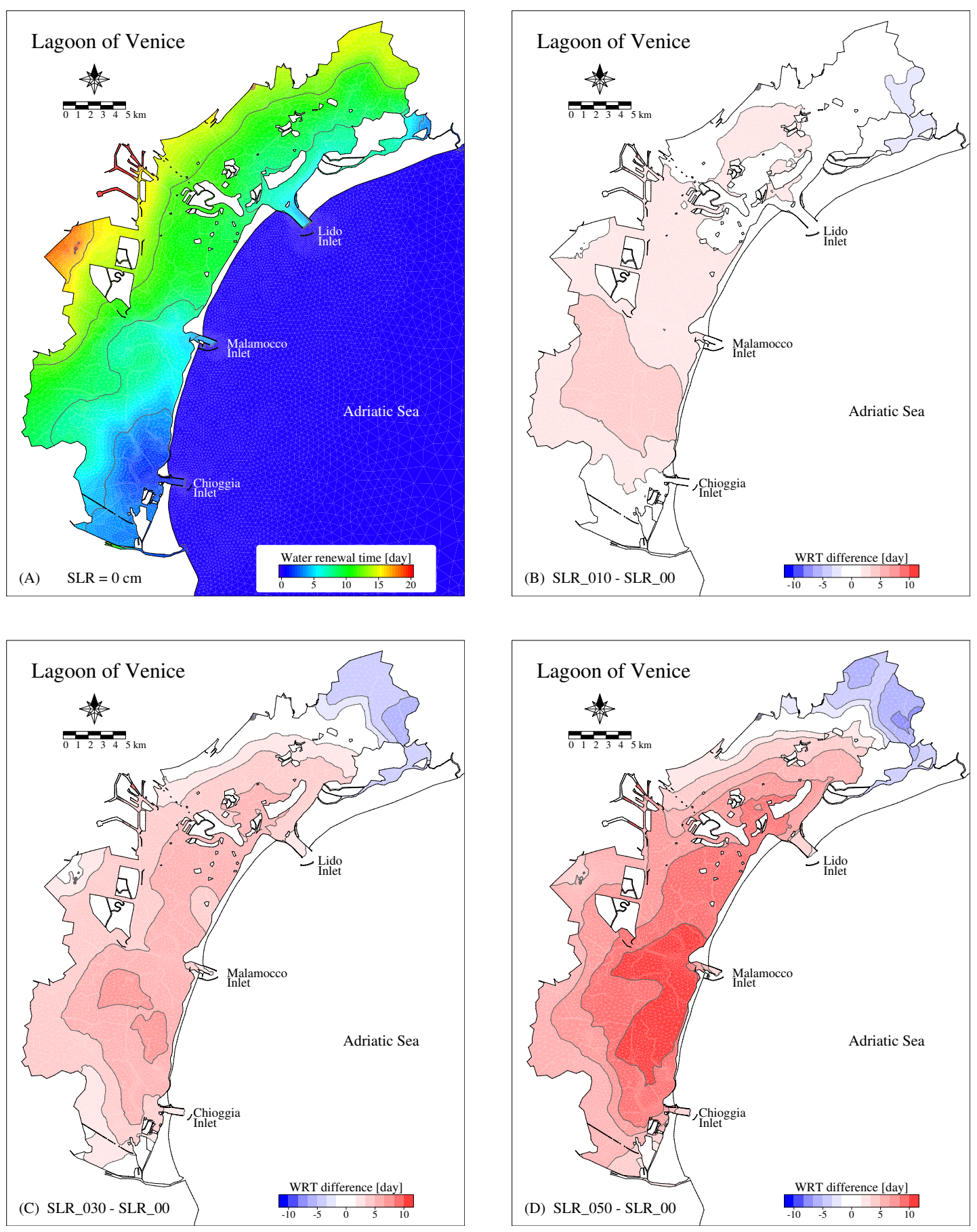

Fig. 6. Map of water renewal time computed by the model for the SLR-00 scenario considering the closure of the inlets during high water events (A), and maps of WRT difference (in days) between SLR-10 and SLR-00 scenarios (B), between SLR-30 and SLR-00 scenarios (C) and between SLR-50 and SLR-00 scenarios (D). The period of reference is November 2002.

From 1927 to 2002 the decrease in WRT well correlates with the increase of water fluxes through the inlets. However, the water volume increases, mostly due to the deepening of the lagoon and loss of marsh areas in the inner lagoon, and the daily fraction of water volume exchanged with the coastal sea decreases. This apparent contradiction is due to the fact that the loss of morphological heterogeneity in the lagoon (lowering of tidal flats, infilling of tidal channels and reduction of salt marsh areas) enhanced the internal water mixing processes driven by the tide and wind. The flattening 


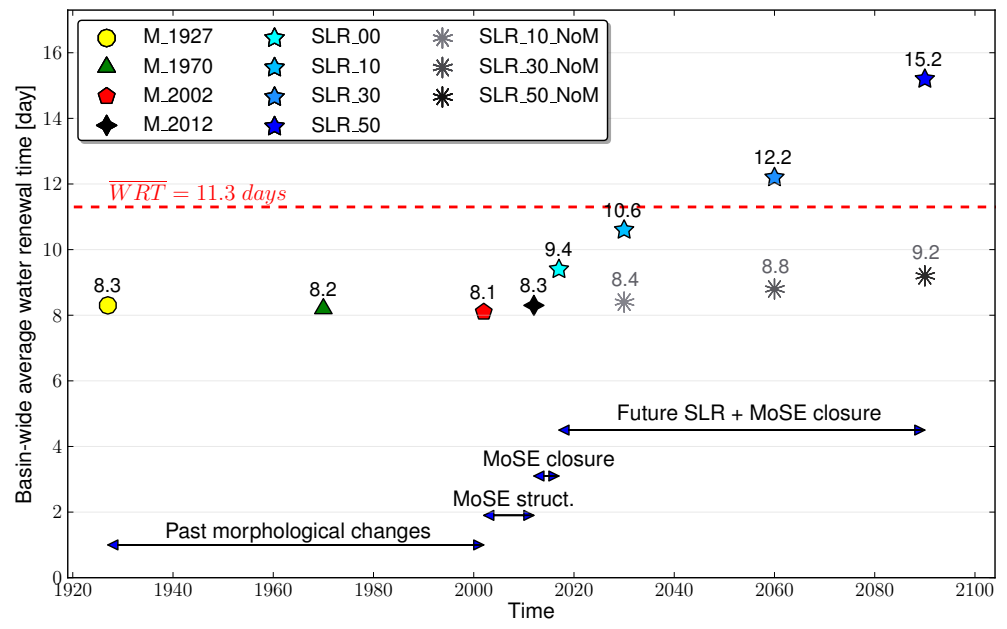

Fig. 7. Evolution of average water renewal time in the Venice Lagoon under fall-winter conditions considering past morphological changes, the MoSE structures, the closure of MoSE barriers during high tide events and future sea level rise of 10, 30 and $50 \mathrm{~cm}$. Gray asterisks indicate the results of SLR simulations without considering closure of the mobile barriers at the inlets (SLR_10_NoM, SLR_20_NoM, SLR_30_NoM). The red dashed line at WRT $=11.3$ days indicates the average yearly value of the present situation $(2012$, simulation Y_2012).

of the lagoon had thus a positive effect on the overall renewal capacity of the basin, which counteracts the negative effect induced by the increase in volume.

The most conspicuous changes in WRT spatial distribution shown in Fig. 4c between 1970 and 2000 can be explained by the effects of the excavation of Malamocco-Marghera navigation channel and recent construction of artificial salt marshes.

The increase of water renewal time from 2002 to 2012 is due to the new structures at the inlets that modify the local circulation and determine a longer retention of water masses in the areas around the inlets as highlighted by the highest value of the return flow factor (Table 3).

With increasing sea level rise, the number of high water events and closure periods increases. While in the present situation the closures are only related to storm surges, in the future scenarios of SLR the barriers are expected to operate also for very high tides related to purely astronomical forcings. Model results clearly show that sea level rise increases the lagoon water volume and closure of the MoSE gates reduces water fluxes through the inlets. The Venice Lagoon will then become progressively more isolated and, as a consequence, the average renewal time of the lagoon's water will increase.

Basin-wide average water renewal time of simulations which considers SLR without any closure of the inlets during high tide events are 8.4, 8.8 and 9.2 days for an SLR of 10, 30 and $50 \mathrm{~cm}$ respectively. Increase in the $\overline{\mathrm{WRT}}$ is only due in this case to increase in the lagoon volume that is not fully compensated by the increase of water fluxes through the inlets. As shown in Fig. 7, where results of these simulations are presented as gray asterisks, the closure of the MoSE barriers is responsible for about the $90 \%$ of the total change in
$\overline{\mathrm{WRT}}$, and therefore it will have a stronger effect on water renewal in comparison with only the increase of volume induced by SLR.

In the present configuration (2012), the value of water renewal time during strong Scirocco winds is three days lower than the average value computed in the yearly simulation (8.3 with respect to 11.3 days). Figure 7 shows that a sea level rise between 10 and $30 \mathrm{~cm}$ leads to a $\overline{\mathrm{WRT}}$ higher than the present (2012) yearly averaged value (red dotted line). The obtained results indicate that the closure of the inlets during storm surges and very high tides to prevent flooding in Venice makes Scirocco winds less effective in renewing the lagoon's waters. Consequently, the internal circulation redistributes the tracer and has more influence on the spatial distribution of the water renewal time than the exchange with the sea.

Model results could also be used to investigate the historical and future hydromorphological evolution of Venice Lagoon. According to Kjerfve and Magill (1989), coastal lagoons can conveniently be subdivided into choked, restricted and leaky systems based on the degree of water exchange between lagoon and ocean. Even if no clear and sharp distinction among hydromorphological types exists, according to this classification, Venice Lagoon may be defined between leaky and restricted.

Lagoon type classification was archived in this study according to $\overline{\text { WRT }}$ and to daily fraction of lagoon water volume exchanged with the open sea (Fig. 8). The figure reports also the numerical results, obtained by applying the same model SHYFEM, of five other Mediterranean lagoons: the MaranoGrado Lagoon in the northern Adriatic Sea, the Taranto basin in the Ionian Sea, the Cabras Lagoon in Sardinia, the Mar Menor in Spain and the Nador Lagoon in Morocco. Details 


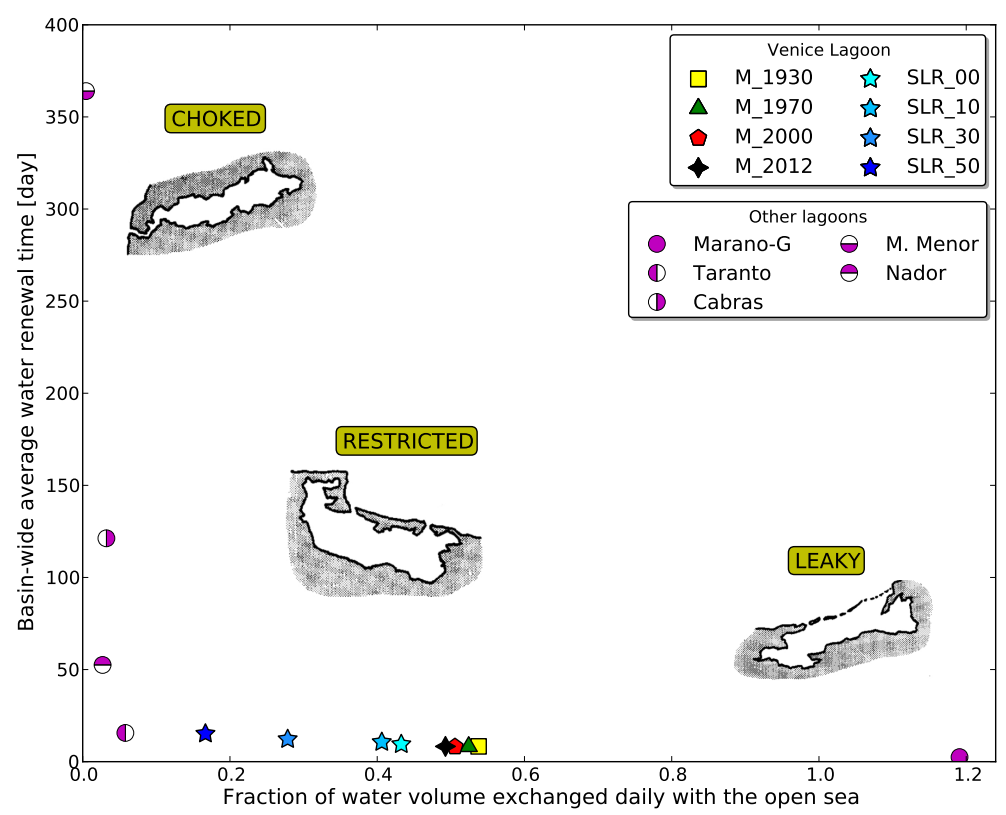

Fig. 8. Evolution of lagoon type, based on water exchange between lagoon and ocean and WRT, in the different scenarios under fallwinter conditions. Leaky, restricted and choked water body sketches are from Kjerfve and Magill (1989). Numerical results of five other Mediterranean lagoons are marked with filled and half-filled magenta circles.

of model application to these lagoons can be found in Magni et al. (2008), Ferrarin et al. (2010b), Umgiesser et al. (2011) and De Pascalis et al. (2011). These environments range from a leaky type to a choked type of basins and give a representative picture of the coastal lagoons situated around the Mediterranean Sea.

Figure 8 shows that Venice Lagoon in the last century did undergo slight changes in hydromorphological type, with a shift towards a more restricted system since the daily fraction of water volume exchanged with the coastal sea decreases. The MoSE structures reduce the exchange with the sea and slightly increase the overall water renewal time. Simulations of future scenarios indicate an evolution towards a more restricted environment. The fraction of water volume exchanged daily with the open sea decreases from 0.49 of the present situation (M_2012) to 0.17 in the case of an SLR of $50 \mathrm{~cm}$. Such a marked decrease depends on two factors: first, the closure of barriers during high tide events limits mechanically the water flow between the lagoon and the sea; second, SLR induces a water volume increase in the basin that is only partially compensated by the increase in water exchange through the inlets.

\subsection{Hydroecological implications}

The presented model results can be used to improve our understanding of the links between physics, hydrology and ecosystem conditions. To properly understand the effects of the hydrological changes we must remember the peculiar ecological structure of lagoons, which are characterised by progressive changes in the main environmental variables, such as salinity, water renewal, nutrients, turbidity and sediment structure that generate composite sea-land gradients (Tagliapietra et al., 2009). These environmental gradients influence directly the structure of biological assemblages selecting sensitive species (Peasron and Rosenberg, 1978; Guelorget and Perthuisot, 1983, 1989).

At a functional level, the sequence from the sea towards more and more confined areas provides a succession of species from "sensitive species", K-strategists (Pianka, 1970) characteristics of the less confined habitats, to "opportunistic species" (Grassle and Grassle, 1974) characterized by type " $r$ " reproductive strategy (r-strategists) that dominate under conditions of intense disturbance. This is accompanied by a progressive decrease in the number of species. Nevertheless often in lagoons resident species show "K features" as far as the reproductive strategy is concerned (e.g. few larvae born at an advanced stage of development) combined with " $r$ features" as far as the life-style is concerned (e.g. short living, fast-growing animals) as evidenced by Barnes (1980) in invertebrates and by Pérez-Ruzafa et al. (2012) in fishes.

Together with the variation of salinity, one of the main mechanisms responsible for this seriation of species and reduction of biodiversity along the gradient is the increase of saprobity, defined as the state of the environment resulting from the input and decomposition of organic matter and the removal of its catabolites (Tagliapietra et al., 2012b). The inner areas of the lagoons are therefore naturally the most saprobic and host communities more tolerant towards the 
accumulation of organic matter, towards catabolites arising from degradation, and to hypoxic and reducing conditions.

The rate of accumulation of nutrients, organic matter and pollutants in semi-closed systems can be proportional to water transport timescale (Dettmann, 2001). This process depends on the accumulation rate of substances in respect to the auto-depurative capacity of the system. Altering the balance of these two processes can mean a shift of environmental conditions and consequentially a different habitat typology, community composition and distribution (Guelorget and Perthuisot, 1989).

Significant changes in water chemistry have overlapped to hydrological changes in the last century, producing vegetal and animal trophic effects (Sfriso et al., 1992; Tagliapietra et al., 1998; Solidoro et al., 2010). The increase of nutrient inputs in the 80-90s caused a succession of aquatic vegetation from seagrasses to fast-growing macroalgae (Sfriso et al., 2003; Sfriso and Facca, 2007). The consequent disproportionate increase of catabolites generated by the degradation of organic matter was not balanced by an adequate water exchange, producing an accumulation of toxic catabolites and an increase of the reducing conditions, flowing finally in dystrophic crisis.

The changes in hydrological conditions could be partly responsible for the evolution observed from 1970 to the present in the zooplankton community structure (Acri et al., 2004; Solidoro et al., 2010). The increased exchange with the sea and the shortening of the WRT, mainly in the inner area of the Venice Lagoon, well correlate with the shift in mesozooplankton composition, with occurrence of the copepod Acartia tonsa Dana, now the dominant Acartia species in the inner and middle part of the basin, and decrease of Acartia lasetinosa, typical of confined environments (Mauchline, 1998).

Scenarios with an SLR from 0 to $50 \mathrm{~cm}$ (Fig. 6) propose a lagoon in which the hydrology of the various habitats is profoundly changed: the banded zonation with increasing confinement from sea to land, shifts to a lagoon characterized by a more concentric confinement gradient, in which the circulation is more influenced by the wind and that looks more like a choked Mediterranean lagoon (coastal pond). In the most extreme simulation (SLR $50 \mathrm{~cm}$ ), the area with higher water renewal time moves from the edge of the lagoon towards central parts of the lagoon, coinciding with the watershed (divide) between the basins of Lido and Malamocco, spreading up to and including the city of Venice. There is a reduction of the land-sea gradient of confinement, resulting in a homogenization of communities in many parts of the lagoon. The higher the level of the sea, and the frequency of closures, the more the lagoon will be increasingly confined with a reduction of water exchange, resulting in a possible reduction of species with marine affinities, more sensitive to saprobic conditions.

The numerical simulations of future scenarios focus on the period of maximum closure of the inlets (autumn) which co- incides with the highest load of sediments, nutrients and pollutants. If these inputs from the hinterland and the City of Venice will not change, there will be a possible entrapment of toxic substances in the central areas of the lagoon, with increased eutrophication and saprobity and risk of anoxia that would also involve the historical city. The lagoon will have to rely almost exclusively on the internal metabolic processes for the assimilation and mineralization of the nutrient inputs. If nutrients and pollutants are not biologically, chemically or geologically retained in the system, they may be flushed during the following winter, otherwise in spring they will trigger the growth of algae (Tagliapietra et al., 2012a). The eutrophic conditions may also lead to the reduction of seagrass, currently in the recovery phase, with drastic effects on biodiversity. Among others, the zone with lower water renewal time is situated in the area where there is now a higher harvesting of Manila clams which might suffer a considerable reduction.

The benthic community could assume a structure more similar to that of the communities currently present in the peripheral areas of the central basin close to the salt marsh fringe. The hypothesized conditions will affect the most sensitive species needing oxygenated waters, including many species of molluscs, and favouring resistant species, tolerant and opportunistic, among them mainly small polychaetes. The communities will therefore be less different, composed of more tolerant species, and in which the vigor is expressed in increasing the number of individuals of small dimensions rather than in increased biomass as it conversely happens in less impacted situations. Moreover a general increase in polychaetes, and a reduction in bivalves could occur, but also face a less favourable environment for many species of fish, including the prized sea bream and bass more favourable to mullets.

In future scenarios the connectivity with the sea will be reduced, limiting the incoming passive particles and migratory organisms, and increasing the relevance of the recirculation and redistribution inside the lagoon. Since Venice Lagoon plays a nursery role for several species, the larval colonisation and the fish migration can be disturbed by the limited connectivity and this could have some consequences on the recruitment (Cowen et al., 2005).

\section{Conclusions}

In the recent morphological history of the Venice Lagoon (1927-2012) several steps can be recognized as important interventions affecting hydromorphological structures and processes. This study aims to relate the general geomorphological changes to the hydrological and ecological consequence.

Human activities in the period 1927-2002 (salt marshes destruction to reclaim land and dredging of the ship channel), and hydromorphological responses to such activities (lowering of tidal flats, infilling of tidal channels and reduction of 
salt marsh areas) increased the water volume of the lagoon and enhanced the internal mixing induced by tide and wind. The mixing processes counteract the increase of water volume due to the deepening of the lagoon and caused a reduction of the overall lagoon's water renewal time (from 11.9 to 10.8 days). The MoSE structures, even without operating the mobile barriers, reduced the water exchange through the inlets and determined a longer retention of water masses in the areas around the inlets resulting in a general loss of flushing capacity. From 1927 to the present the lagoon slowly moved towards a more restricted coastal system.

The future scenario of SLR and operation of mobile barriers at the inlets makes the Venice Lagoon similar to an artificially semi-closed basin and the limited sea-lagoon water exchange, mostly in the fall-winter months, implies that in these conditions the dynamics of the ecosystem becomes a recirculation. Simulated basin-wide average water renewal time under winter conditions increased from 8.3 days in the present situation to 15.2 days in the scenario with a sea level rise of $50 \mathrm{~cm}$. It has to be noted that the future increase in water renewal time is more evident in the central part of the lagoon, where most of the pollutant sources are located. This implies that the area close to the city of Venice and close to the industrial zone will experience the most intense ecological consequences of the human-induced, locally and globally, modifications.

The effects on the biota of eutrophication and saprobity depend on the balance between the input of organic matter, the rate of degradation and the output from the system of toxic catabolites and excess nutrients. In the lagoons, the output is determined by the exchanges with the sea. In the past, the lagoon has undergone dystrophic crisis as the inputs of nutrients, biomass and catabolites generated by its degradation were so high that they could not be compensated by exports to the sea and intakes of clean water. With the assumed future situation, i.e. with long renewal times, the situation may reoccur with an accumulation of catabolites and nutrients due not so much to an increase of inputs, as to a decrease of outputs.

The maximum sea level rise considered in this study was $50 \mathrm{~cm}$, but recent prediction suggested an end-of-century scenario of more than $60 \mathrm{~cm}$, not excluding the chance of a $100 \mathrm{~cm}$ increase (Umgiesser et al., 2012). Such an SLR will worsen the ecological implications of a further decrease of sea-lagoon water exchange and of the increasing water renewal time discussed in this study. Moreover, the expected increase in temperature during this century will make the situation worse (Tagliapietra et al., 2011).

In an increasingly confined lagoon, the management of nutrients, pollutants and organic matter inputs from the drainage basins, but also from population centers, will become vital. Therefore, the developed modelling approach, which describes the spatial heterogeneity of the renewal and mixing behaviour of coastal lagoons, is essential to manage these important ecosystems.
Acknowledgements. The authors wish to thank Stefano Guerzoni for his guidance and help. This research was partially funded by Ministero delle Infrastrutture e dei Trasporti - Magistrato alle Acque di Venezia, through Co.Ri.La, under the research program "La Laguna di Venezia nel quadro dei cambiamenti climatici, delle misure di mitigazione ed adattamento e dell'evoluzione degli usi del territorio" and partially by the Flagship Project RITMARE - The Italian Research for the Sea - coordinated by the Italian National Research Council and funded by the Italian Ministry of Education, University and Research within the National Research Program 2011-2013.

Edited by: A. D. Reeves

\section{References}

Abdelrhman, M. A.: Simplified modeling of flushing and residence times in 42 embayments in New England, USA, with special attention to Greenwich Bay, Rhode Island, Estuar. Coast. Shelf Sci., 62, 339-351, 2005.

Acri, F., Aubry, F. B., Berton, A., Bianchi, F., Boldrin, A., Camatti, E., Comaschi, A., Rabitti, S., and Socal, G.: Plankton communities and nutrients in the Venice Lagoon, comparison between current and old data, J. Mar. Syst., 51, 321-329, 2004.

Allison, I., Bindoff, N., and Bindschadler, R: The Copenhagen diagnosis: updating the world on the latest climate science, The University of New South Wales Climate Change Research Centre (CCRC), Sydney, Australia, 60 pp., 2009.

Barners, R. S. K.: Coastal Lagoons, The Natural History of a Neglected Habitat, Cambridge Studies in Modern Biology 1, Cambridge University Press, Cambridge, UK, 106 pp., 1990.

Blumberg, A. and Mellor, G. L.: A description of a threedimensional coastal ocean circulation model, in: ThreeDimensional Coastal Ocean Models, edited by: Heaps, N. S. American Geophysical Union, Washington, DC, 1-16, 1987.

Bruneau, N., Fortunato, A. B., Dodet, G., Freire, P., Oliveira, A., and Bertin, X.: Future evolution of a tidal inlet due to changes in wave climate, Sea level and lagoon morphology (Obidos lagoon, Portugal), Cont. Shelf Res., 31, 1915-1930, 2011.

Burchard, H. and Petersen, O.: Models of turbulence in the marine environment - a comparative study of two equation turbulence models, J. Mar. Syst., 21, 29-53, 1999.

Carbognin, L., Teatini, P., Tomasin, A., and Tosi, L.: Global change and relative sea level rise at Venice: what impact in term of flooding, Clim. Dynam., 35, 1039-1047, 2010.

Carniello, L., Defina, A., and D'Alpaos, L.: Morphological evolution of the Venice lagoon: evidence from the past and trend for the future, J. Geophys. Res., 114, F04002, doi:10.1029/2008JF001157, 2009.

Chubarenko, B., Koutitonsky, V. G., Neves, R., and Umgiesser, G.: Modeling concepts, in: Coastal Lagoons: Ecosystem Processes and Modelling for Sustainable Use and Development, edited by: Gönenç, I. E. and Wolflin, J. P., CRC Press, Boca Raton, FL, USA, 193-229, 2005.

Cowen, R. K., Paris, C. B., and Srinivasan, A.: Scaling of connectivity in marine populations, Science, 311, 522-527, 2005. 
Cucco, A. and Umgiesser, G.: Modelling the Venice Lagoon residence time, Ecol. Model., 193, 34-51, 2006.

Cucco, A., Umgiesser, G., Ferrarin, C., Perilli, A., Melaku Canu, D., and Solidoro, C.: Eulerian and lagrangian transport time scales of a tidal active coastal basin, Ecol. Model., 220, 913-922, 2009.

D'Alpaos, L.: L'evoluzione morfologica della Laguna di Venezia attraverso la lettura di alcune mappe storiche e delle sue carte idrografiche, Comune di Venezia, Istituzione Centro Previsioni e Segnalazioni Maree, 2010.

Day, J. W., Rismondo, A., Scarton, F., Are, D. and Cecconi, G.: Relative sea level rise and Venice lagoon wetlands, J. Coast. Conserv., 4, 27-34, 1998.

Day, J. W., Ibàn̄ez, C., Scarton, F., Pont, D., Hensel, P., Day, J., and Lane, R.: Sustainability of Mediterranean Deltaic and Lagoon Wetlands with Sea-Level Rise: The Importance of River Input, Estuar. Coast., 34, 483-493, 2011.

de Brye, B., de Brauwere, A., Gourgue, O., Delhez, E. J., and Deleersnijder, E.: Water renewal timescales in the Scheldt Estuary, J. Mar. Syst., 94, 74-86, 2012.

De Pascalis, F., Pérez-Ruzafa, A., Gilabert, J., Marcos, C., and Umgiesser, G.: Climate change response of the Mar Menor coastal lagoon (Spain) using a hydrodynamic finite element model, Estuar. Coast. Shelf Sci., 114, 118-129, 2011.

Dettmann, E.: Effect of water residence time on annual export and denitrification of nitrogen in estuaries: a model analysis, Estuar. Coast., 24, 481-490, 2001.

Duck, R. W. and da Silva, J. F.: Coastal lagoons and their evolution: a hydromorphological perspective. Estuar. Coast. Shelf Sci., 110, 2-14, 2012.

Ferrarin, C. and Umgiesser, G.: Hydrodynamic modeling of a coastal lagoon: the Cabras lagoon in Sardinia, Italy, Ecol. Model., 188, 340-357, 2005.

Ferrarin, C., Razinkovas, A., Gulbinskas, S., Umgiesser, G., and Bliūdžiute, L.: Hydraulic regime based zonation scheme of the Curonian Lagoon, Hydrobiologia, 611, 133-146, 2008.

Ferrarin, C., Cucco, A., Umgiesser, G., Bellafiore, D., and Amos, C. L.: Modelling fluxes of water and sediment between the Venice Lagoon and the sea, Cont. Shelf Res. 30, 904-914, 2010a.

Ferrarin, C., Umgiesser, G., Bajo, M., De Pascalis, F., Ghezzo, M., Bellafiore, D., Mattassi, G., and Scroccaro, I.: Hydraulic zonation of the Lagoons of Marano and Grado, Italy, a modelling approach, Estuar. Coast. Shelf Sci., 87, 561-572, 2010 b.

Gamito, S., Gilabert, J., Diego, C. M., and Pérez-Ruzafa, A.: Effect of Changing Environmental Conditions on Lagoon Ecology, in: Coastal Lagoons: Ecosystem Processes and Modelling for Sustainable Use and Development, edited by: Gönenç, I. E. and Wolflin, J. P., CRC Press, Boca Raton, FL, USA, 193-229, 2005.

Ghezzo, M., Guerzoni, S., Cucco, A., and Umgiesser, G.: Changes in Venice Lagoon dynamics due to construction of mobile barriers, Coast. Eng., 57, 694-708, 2010.

Gong, W., Shen, J., and Jia, J.: The impact of human activities on the flushing properties of a semi-enclosed lagoon: Xiaohai, Hainan, China, Mar. Environ. Res., 65, 62-76, 2008.

Grassle, J. F. and Grassle, J. P.: Opportunistic life histories and genetic systems in marine benthic polychaetes, J. Mar. Res., 32, 253-284, 1974.
Guelorget, O. and Perthuisot, J. P.: Le domaine paralique, Expressions géologiques, biologiques et économiques du confinement, Travaux du Laboratoire de Geólogie, Ecole Normale Supeŕieure de Paris 16, 1-136, 1983.

Guelorget, O. and Perthuisot, J. P.: The Paralic Realm, Geological, Biological and Economic Expression of Confinement, Tech. Rep. FAO-FI-RAB/83/016, FAO, Rome, 1989.

Guerzoni, S. and Tagliapietra, D.: Atlas of the lagoon: Venice between land and sea, Marsilio, Venezia, IT, 2006.

Hartnett, M., Nash, S., and Olbert, I.: An integrated approach to trophic assessment of coastal waters incorporating measurement, modelling and water quality classification, Estuar. Coast. Shelf Sci., 112, 126-138, 2012.

Jaffe, B. E., Smith, R. E., and Foxgrover, A. C.: Anthropogenic influence on sedimentation and intertidal mudflat change in San Pablo Bay, California: 1856-1983, Estuar. Coast. Shelf Sci., 7, 175-187, 2007.

Jouon, A., Douillet, P., Ouillon, S., and Fraunié, P.: Calculations of hydrodynamic time parameters in a semi-opened coastal zone using a 3d hydrodynamic model, Cont. Shelf Res., 26, 13951415, 2006.

Kjerfve, B. and Magill, K. E.: Geographic and hydrodynamic characteristics of shallow coastal lagoons, Mar. Geol., 88, 187-199, 1989.

Liu, W.-C., Chen, W.-B., Kuo, J.-T., and Wu, C.: Numerical determination of residence time and age in a partially mixed estuary using three-dimensional hydrodynamic model, Cont. Shelf Res., 28, 1068-1088, 2008.

Magni, P., Como, S., Cucco, A., De Falco, G., Domenici, P., Ghezzo, M., Lefrançois, C., Simeone, S., and Perilli, A.: A multidisciplinary and ecosystemic approach in the Oristano LagoonGulf system (Sardinia, Italy) as a tool in management plans, Transit. Water. Bull., 2, 41-62, 2008.

Mauchline, J.: The biology of marine copepods, Adv. Mar. Biol., 33, 710 pp., 1998.

Melaku Canu, D., Umgiesser, G., and Solidoro, C.: Short-term simulations under winter conditions in the lagoon of Venice: a contribution to the environmental impact assessment of temporary closure of the inlets, Ecol. Model., 138, 215-230, 2001.

Molinaroli, E., Guerzoni, S., Sarretta, A., Cucco, A., and Umgiesser, G.: Links between hydrology and sedimentology in the Lagoon of Venice, Italy, J. Mar. Syst., 68, 303-317, 2007.

Monsen, N. E., Cloern, J. E., and Lucas, L. V.: A comment on the use of flushing time, residence time, and age as transport time scales, Limnol. Oceanogr., 47, 1545-1553, 2002.

Ouillon, S., Douillet, P., Lefebvre, J., Gendre, R. L., Jouon, A., Bonneton, P., Fernandez, J., Chevillon, C., Magand, O., Lefèvre, J., Hir, P. L., Laganier, R., Dumas, F., Marchesiello, P., Madani, A. B., Andréfouet, S., Panché, J., and Fichez, R.: Circulation and suspended sediment transport in a coral reef lagoon: the south-west lagoon of New Caledonia, Mar. Pollut. Bull., 61, 269-296, 2010.

Peasron, T. and Rosenberg, R.: Macrobenthic succession in relation to organic enrichment and pollution of the marine environment, Oceanogr. Mar. Biol. Ann. Rev., 16, 229-311, 1978.

Pérez-Ruzafa, A., Mompeàn, M. C., and Concepción, M.: Hydrographic, geomorphologic and fish assemblage relationships in coastal lagoons, Hydrobiologia, 577, 107-125, 2007. 
Pérez-Ruzafa, A., Marcos, C., Pérez-Ruzafa, I. M., and PérezMarcos, M.: Coastal lagoons: "transitional ecosystems" between transitional and coastal waters, J. Coast. Conserv., 15, 369-392, 2011.

Pérez-Ruzafa, A., Marcos, C., Pérez-Ruzafa, I. M., and PérezMarcos, M.: Are coastal lagoons physically or biologically controlled ecosystems? Revisiting $\mathrm{r}$ vs. K strategies in coastal lagoons and estuarie, Estuar. Coast. Shelf Sci., doi:10.1016/j.ecss.2011.08.012, in press, 2012.

Pianka, E. R.: On r- and K-selection, Am. Naturalist, 104, 592-597, 1970.

Plus, M., Dumas, F., Stanisière, J.-Y., and Maurer, D.: Hydrodynamic characterization of the Arcachon Bay, using modelderived descriptors, Cont. Shelf Res., 29, 1008-1013, 2009.

Rodhe, H.: Modeling biogeochemical cycles, in: Global Biogeochemical Cycles, edited by: Butcher, S. S., Charlson, R. J., Orians, G. H., and Wolfe, G. V., Academic Press, London, UK, 5572, 1992.

Roselli, L., Can̄edo-Argüelles, M., Costa Goela, P., Cristina, S., Rieradevall, M., D'Adamo, R., and Newton, A.: Do physiography and hydrology determine the physico-chemical properties and trophic status of coastal lagoons? A comparative approach, Estuar. Coast. Shelf Sci., 117, 29-36, 2013.

Sanford, L., Boicourt, W., and Rives, S.: Model for estimating tidal flushing of small embayments, J. Waterway Port Coast. Ocean Eng., 118, 913-935, 1992.

Sarretta, A., Molinaroli, E., Guerzoni, S., Fontolan, G., and Pillon, S.: Sediment budget in the Lagoon of Venice, Cont. Shelf Res., 30, 934-949, 2010.

Sfriso, A. and Facca, C.: Distribution and production of macrophytes and phytoplankton in the lagoon of Venice: comparison of actual and past situation, Hydrobiologia, 577, 71-81, 2007.]

Sfriso, A., Pavoni, B., Marcomini, A., and Orio, A. A.: Macroalgae, nutrient cycles and pollutants in the lagoon of Venice, Estuaries, 15, 517-528, 1992.

Sfriso, A., Facca, C., and Ghetti, P. F.: Temporal and spatial changes of macrolagae and phytoplankton in a Mediterranean coastal area: the Venice Lagoon as a case study, Mar. Environ. Res., 56, 316-336, 2003.

Smagorinsky, J.: General circulation experiments with the primitive equations, I. the basic experiment, Mon. Weather Rev., 91, 99$152,1963$.

Solidoro, C., Bandelj, V., Bernardi Aubry, F., Camatti, E., Ciavatta, S., Cossarini, G., Facca, C., Franzoi, P., Libralato, S., Melaku Canu, D., Pastres, R., Pranovi, F., Raicevich, S., Socal, G., Sfriso, A., Sigovini, M., Tagliapietra, D., and Torricelli, P.: Response of Venice Lagoon ecosystem to natural and anthropogenic pressures over the last 50 years, in: Coastal Lagoons: Critical Habitats of Environmental Change, edited by: Kennish, M. J. and Paerl, H. W., CRC Press, Boca Raton, FL, USA, 483-511, 2010.
Tagliapietra, D., Pavan, M., and Wagner, C.: Macrobenthic community changes related to eutrophication in Palude della Rosa (Venetian lagoon, Italy), Estuar. Coast. Shelf Sci., 47, 217-226, 1998.

Tagliapietra, D., Sigovini, M., and Volpi Ghirardini, A.: A review of terms and definitions to categorise estuaries, lagoons and associated environments, Mar. Freshwater Res., 60, 497-509, 2009.

Tagliapietra, D., Zanon, V., Frangipane, G., Umgiesser, G., and Sigovini, M.: Physiographic zoning of the Venetian Lagoon, in: Scientific Research and Safeguarding of Venice, Research program 2007-2010, 2004 Results, CORILA, Venice, 161-164, 2011.

Tagliapietra, D., Aloui-Bejaoui, N., Bellafiore, D., Wit, R. D., Ferrarin, C., Gamito, S., Lasserre, P., Magni, P., Mistri, M., PérezRuzafa, A., Pranovi, F., Reizopoulou, S., Rilov, G., Solidoro, C., Tunberg, B., Valiela, I., and Viaroli, P.: The Ecological Implications of Climate Change on the Lagoon of Venice, Tech. rep., UNESCO Venice Office, Venice, 45 pp., 2012a.

Tagliapietra, D., Sigovini, M., and Magni, P.: Saprobity: a unified view of benthic succession models for coastal lagoons, Hydrobiologia, 686, 15-28, 2012b.

Takeoka, H.: Fundamental concepts of exchange and transport time scales in a coastal sea, Cont. Shelf Res., 3, 327-341, 1984.

Umgiesser, G.: Modelling the residual current in the Venice Lagoon, in: Interaction between Estuaries, Coastal Seas and Shelf Seas, edited by: Yanagi, T., Terra Scientific Publishing Company, Tokyo, 107-124, 2000.

Umgiesser, G. and Bergamasco, A.: Outline of a Primitive Equations Finite Element Model, Rapporto e Studi, Istituto Veneto of Scienze, Lettere ed Arti XII, Venice, Italy, 291-320, 1995.

Umgiesser, G. and Matticchio, B.: Simulating the mobile barrier (MOSE) operation in the Venice Lagoon, Italy: global sea level rise and its implication for navigation, Ocean Dynam., 56, 320332, 2006.

Umgiesser, G., Melaku Canu, D., Cucco, A., and Solidoro, C.: A finite element model for the Venice Lagoon. Development, set up, calibration and validation, J. Mar. Syst. 51, 123-145, 2004.

Umgiesser, G., Ferrarin, C., Cucco, A., Pérez Ruzafa, A., De Pascalis, F., Ghezzo, M., Bellafiore, D., and Bajo, M.: A comparison study of six Mediterranean lagoons with numerical modelling, in: Rassegna delle attività di ricerca scientifica e tecnologica del CNR nell' ambito del mare e delle sue risorse, Dipartimento Terra e Ambiente CNR, 1073-1084, 2011.

Umgiesser, G., Anderson, J. B., Artale, V., Breil, M., Gualdi, S., Lionello, P., Marinova, N., Orlic, M., Pirazzoli, P., Rahmstorf, S., Raicich, F., Rohling, E., Tomasin, A., Tsimplis, M., and Vellinga, P.: From Global to Regional: Local Sea Level Rise Scenarios - Focus on the Mediterranean Sea and the Adriatic Sea Tech. rep., UNESCO Venice Office, Venice, 24 pp., 2012.

Viaroli, P., Laserre, P., and Campostrini, P.: Lagoons and coastal wetlands, Dev. Hydrob., 192, 1-3, 2007. 